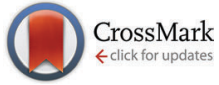

Cite this: J. Mater. Chem. C, 2015, 3, 3350

\title{
Versatile nano-platforms for hybrid systems: expressing spin-transition behavior on nanoparticles $\dagger$
}

\author{
A. Paquirissamy, ${ }^{a}$ A. R. Ruyack, ${ }^{a}$ A. Mondal, ${ }^{a}$ Y. Li, ${ }^{a}$ R. Lescouëzec, ${ }^{a}$ C. Chanéac*b \\ and B. Fleury*a
}

\begin{abstract}
The aim of this paper is to demonstrate the possibility of expressing molecular magnetic phenomena on hybrid nano-particles. The advantage of such composite materials is their wonderful versatility, in terms of choice of molecular compounds to be grafted on, and in terms of possibilities for integration in devices. As a first example, we designed a composite made of silica nanoparticles as cores on which Fe(II) coordination complexes displaying spin-crossover (SCO) phenomenon have been grafted in three steps involving the silanization of the $\mathrm{SiO}_{2}$ core, the anchoring of bis(1-methylimidazolyl)-type ligands and at last the coordination of octahedral Fe(॥) complexes at the surface of the nanoparticles. This step-by-step procedure enables an adequate coverage of the Fe(॥) complexes at the surface of the nanoparticles that allows for the appearance of the spin-transition (ST) behavior at a level detectable by SQUID magnetometry. These tailor-made particles can thus be considered as nanometric switchable units.
\end{abstract}

Received 5th January 2015,
Accepted 12th February 2015

DOI: $10.1039 / c 5 t c 00021 a$

www.rsc.org/MaterialsC
Among SCO-compounds, $\mathrm{Fe}(\mathrm{II})$ octahedral complexes are of particular interest since the $3 \mathrm{~d}^{6}$ valence shell may exist in either a low-spin $(\mathrm{LS})$ and diamagnetic $(S=0)$ configuration, or a highspin (HS) and paramagnetic $(S=2)$ state. The LS/HS transition can be triggered by external stimuli such as temperature, pressure or light. ${ }^{21}$ While the mechanisms triggering the SCO phenomenon at the nanoscale are intricate and still difficult to elucidate, the interactions of the SCO units with their environment are known to be of crucial importance in the efficiency, temperature and hysteretic behavior of the SCO phenomenon. ${ }^{22-25}$ In order to both understand these switching mechanisms and to design efficient integrated ST materials, grafting Fe(II) compounds to nanoparticles provides a relevant approach for experimentation. In the past, the size of ST coordination polymer particles has been reduced and the effect of this reduction ${ }^{15,26-28}$ as well as the effect of the matrix in which the nanoparticles are embedded have been studied. ${ }^{29,30}$ The photocommutation of three-dimensional Hoffmann clathrate $\left[\mathrm{Fe}^{\mathrm{II}}(\right.$ pyrazine $\left.)\right]\left[\mathrm{Pt}(\mathrm{CN})_{4}\right]_{n}$ nanocrystals has also been achieved and studied by $4 \mathrm{D}$ electronic microscopy. ${ }^{31,32}$ Furthermore, ST polymeric chains of $\left[\mathrm{Fe}(\text { aminotriazole })_{3}\right]_{n}{ }^{2+}$ compounds have been processed into composite nanoparticles showing the consistency of their properties. ${ }^{33,34}$ In these examples, $\mathrm{Fe}(\mathrm{II})$-based coordination polymers have solely been used; however, discrete mononuclear complexes confined on nanoparticles have scarcely been studied. Indeed, polymeric compounds are known to facilitate the so-called cooperativity enabled abruptness and bistability of the ST behavior. ${ }^{35}$ On the contrary, the SCO properties of discrete molecular compounds are more difficult 
to predict since the molecules are not confined to their crystal lattice. Beyond understanding the SCO mechanisms arising at the nanoscale, the challenge we would like to address here is the confinement of discrete Fe(II) mononuclear complexes into hybrid nano-materials and the study of the effect this has on the ST properties of the compounds at the macroscopic scale.

\section{Results and discussion}

To do so, we have synthesized hybrid nanoparticles with a silica core on which Fe(II) mononuclear complexes displaying SCO have been confined as a shell. Scheme 1 gives a representation of the molecular architecture of these hybrid spin-transition nanoparticles (HSTNs). Silica has been chosen as the core material since it is easily functionalizable and its growth via the Stöber process produces monodisperse and spherical nanoparticles with well-defined size (diameter range of 5-1000 nm). ${ }^{36-39}$ Functionalization by 3-aminopropyltriethoxysilane (APTES) results in amine-terminated particles due to the native silanol groups at the surface of the silica reacting with the silane function of APTES to form siloxane bridges. ${ }^{40}$ These amino-terminated particles serve as a nano-platform for a wide range of further functionalization thanks to the versatility of the amine reactivity. In order to control the coverage of the ST shell, a sequential synthetic strategy has been chosen, starting from the APTES-functionalized nanoplatforms. Such a strategy requires an appropriate choice of the solvents at each step to ensure the best solubility of the

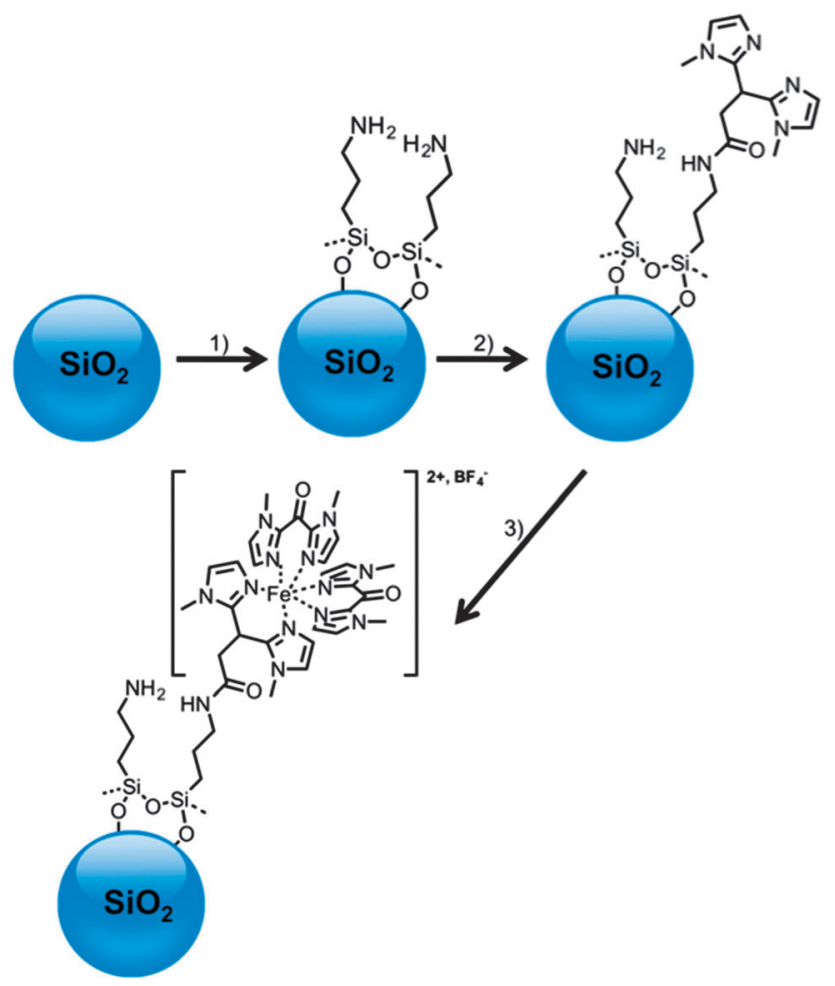

Scheme 1 Representation of the molecular architectures grafted at the surface of silica nanoparticles. (1) 3-Aminopropyltriethoxysilane, $\mathrm{EtOH}$ (2) $\mathrm{HBIP}, \mathrm{EDC}, \mathrm{MeCN}(3)\left[\mathrm{Fe}(\mathrm{BIK})_{2}(\mathrm{MeCN})_{2}\right]\left(\mathrm{BF}_{4}\right)_{2}$. reactants (in order to fully eliminate any excess starting material by simple washing) while at the same time achieving high stability of each newly formed layer. This requirement is particularly important in the case of coordination compounds such as the Fe(II) compounds used in this study because of their inherent lability. Nevertheless, this sequential synthetic approach has already proved to be extremely efficient and accurate in the synthesis of coordination nano-objects at the surface of inorganic substrates. ${ }^{41-44}$ The experimental details of the Fe(II) shell synthesis are given in the experimental section. Briefly, the pending amino groups of the nano-platform are available for peptide coupling to 3,3-bis(1-methylimidazol-2-yl)propionic acid $^{45,46}$ (HBIP) yielding bis-1-methylimidazole (BIP) functionalized particles. Fe(II) ions are then trapped by these surface available ligands and their coordination sphere is completed by two bis(1-methylimidazol-2-yl)ketone (BIK) capping ligands to provide an octahedral geometry around the metallic ions. ${ }^{47}$ Between each step of synthesis the nanoparticles are dutifully freed of any unreacted matter by several cycles of centrifugation and washing with the pure solvent used in the corresponding synthetic step.

In order to check the size and dispersity of the nanoparticles as well as the stability of the silica core during the sequence of grafting, dynamic light scattering (DLS) measurements and TEM images were recorded. From the initial silica synthesis to the final hybrid nanoparticles, TEM images reveal a stable average diameter of $48.5 \pm 6 \mathrm{~nm}$ (Fig. 1). This is in agreement with the stability of the silica nanoparticles, which do not shrink or grow appreciably during the synthetic process. Since DLS measures hydrodynamic diameter, the nanoparticle sizes found using this technique were larger compared to TEM measurements. Bare hydrophilic silica particles in ethanol right after core preparation give a diameter of $79.1 \pm 5.4 \mathrm{~nm}$ while particles in acetonitrile after grafting of the Fe(II) complexes give a diameter of $200 \pm 12 \mathrm{~nm}$. Although DLS does not produce a reliable particle size measurement like TEM, the low disparity in our measurements (less than 10\%) proves the absence of aggregation in our samples.

Monitoring the grafting sequence via ATR-FTIR (ESI $\dagger$ ) reveals the appearance of the $\mathrm{C}=\mathrm{O}$ stretching vibration mode at $1686 \mathrm{~cm}^{-1}$ after amidification with HBIP which is attributed to the primary amide linking BIP to APTES. A second and more

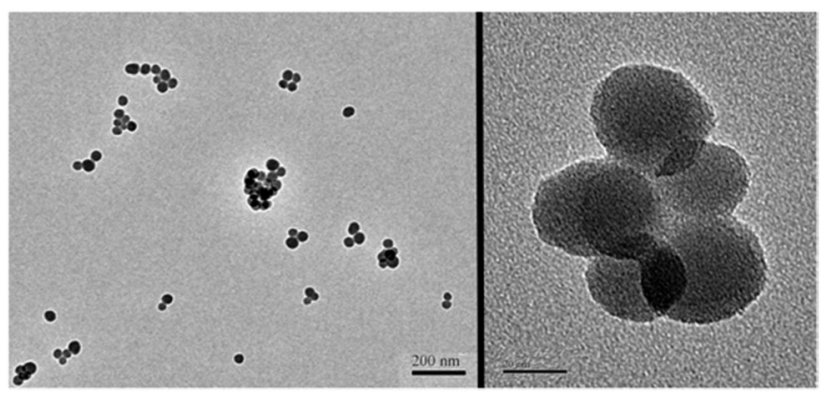

Fig. 1 TEM images of the final hybrid silica nanoparticles. Left: scale bar is $200 \mathrm{~nm}$, right: scale bar is $20 \mathrm{~nm}$. 


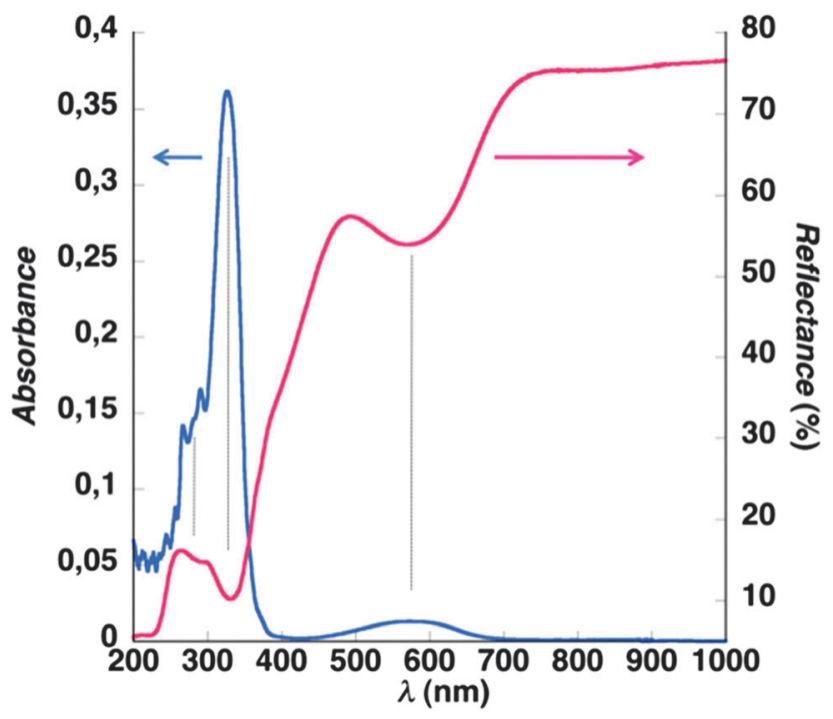

Fig. 2 Absorbance (blue) spectrum of $\left[\mathrm{Fe}(\mathrm{BIK})_{3}\right]\left(\mathrm{BF}_{4}\right)_{2} \cdot 0.25 \mathrm{H}_{2} \mathrm{O}\left(5 \times 10^{-5} \mathrm{M}\right.$ in $\mathrm{MeCN}$ ) and reflectance (pink) spectrum of the final hybrid nanoparticles (dried powder). The vertical dash lines are given as a guide for the eyes.

intense carbonyl vibration mode appears at $1631 \mathrm{~cm}^{-1}$ after complexation of $\mathrm{Fe}(\mathrm{II})$ and BIK corresponding to the ketone function of BIK. Below $1200 \mathrm{~cm}^{-1}$, the FTIR spectrum is dominated by the strong absorption of silica and is not exploited. In order to prove the grafting of $\left[\mathrm{Fe}(\mathrm{BIK})_{2}(\mathrm{BIP})\right]^{2+}$ moieties at the surface of the silica nanoparticles, a UV-Vis reflectance spectrum was recorded in the solid state and compared to the absorption spectrum taken in solution of $\left[\mathrm{Fe}(\mathrm{BIK})_{3}\right]^{2+}$ in acetonitrile (Fig. 2). The three absorption maxima of the lone complex spectrum match exactly with the reflectance minima of the particles spectrum and occur at 290,327, and $577 \mathrm{~nm}$. The transitions at 290 and $327 \mathrm{~nm}$ are attributed to $\pi-\pi^{*}$ transitions centered on the BIK ligand whereas the broad band at $590 \mathrm{~nm}$, also reported for $\left[\mathrm{Fe}(\mathrm{BIK})_{3}\right]^{2+},{ }^{47}$ is reminiscent of the MLCT transition which is commonly observed in octahedral LS-Fe(II) complexes containing alpha-diimine ligands. ${ }^{47,48}$ These observations provide proof for the successful grafting of Fe(II) octahedral complexes based on three bis-1-methylimidazole ligands onto the silica nanoparticles.

In order to both check the consistency of the magnetic properties of the grafted $\mathrm{Fe}(\mathrm{II})$ complexes and their grafting coverage, the product of the mass magnetic susceptibility $\left(\chi_{\mathrm{m}}\right)$ and temperature was recorded on the final hybrid particles as a function of temperature (Fig. 3). Compared to the large silica core, the signal of the magnetic compounds comprising the shell of the particles is relatively small. In order to extract the signal of only the magnetic material the same measurement was performed on diamagnetic silica particles of the same size and the magnetic moments of the two samples were subtracted from each other. ${ }^{49}$ This allows for the measurement of only the magnetic properties of the $\left[\mathrm{Fe}(\mathrm{BIP})(\mathrm{BIK})_{2}\right]\left(\mathrm{BF}_{4}\right)_{2}$ shell. At high temperature, a plateau is observed with a $\chi_{\mathrm{m}} T$ value of $1.2 \times$ $10^{-3} \mathrm{~cm}^{3} \mathrm{~K} \mathrm{~g}^{-1}$. Between $225 \mathrm{~K}$ and $195 \mathrm{~K}$, the $\chi_{\mathrm{m}} T$ drops

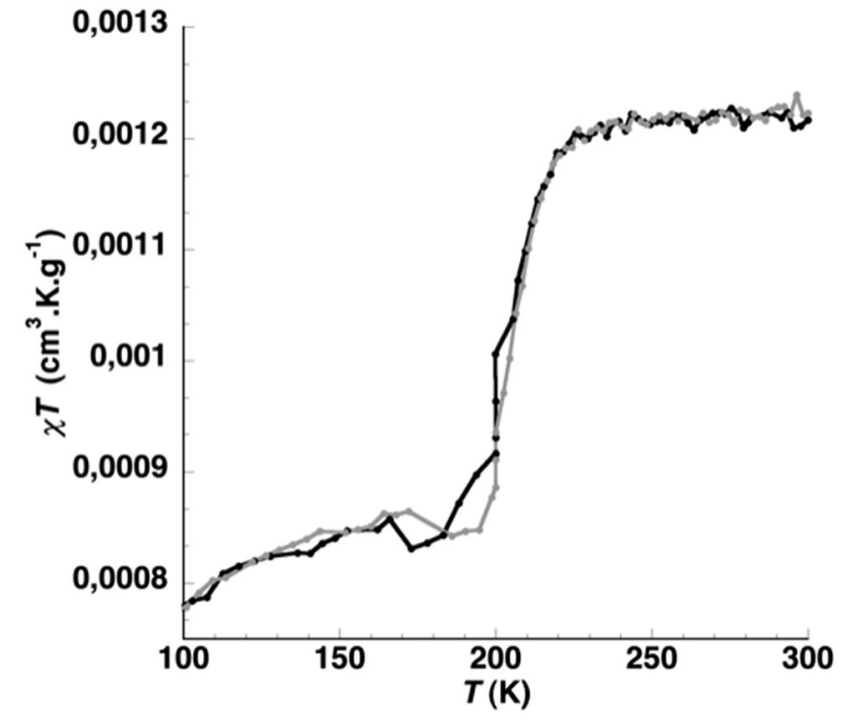

Fig. 3 Product of the mass susceptibility by the temperature of a dried sample of the hybrid nanoparticles, recorded first while cooling from $300 \mathrm{~K}$ to $100 \mathrm{~K}$ (black) and then while heating from $100 \mathrm{~K}$ to $300 \mathrm{~K}$ (grey).

abruptly to $8.5 \times 10^{-4} \mathrm{~cm}^{3} \mathrm{~K} \mathrm{~g}^{-1}$ and then plateaus again at low temperature. This shape is characteristic of a thermal spintransition arising at $T_{1 / 2}=210 \mathrm{~K}$. The $\chi_{\mathrm{m}} T$ value at high temperature is attributed to the HS-Fe(II) complexes $(S=2)$ and the value at low temperature to the complexes in the LS state $(S=0)$. The abruptness of the transition suggests a good level of cooperativity. For comparison, the ST behavior of the bulk compound $\left[\mathrm{Fe}(\mathrm{BIK})_{3}\right]\left(\mathrm{BF}_{4}\right)_{2} \cdot 0.25 \mathrm{H}_{2} \mathrm{O}$ arises at $250 \mathrm{~K}^{50-52}$ The lower spin transition temperature of the hybrid particles is attributed to a modified coordination sphere around the $\mathrm{Fe}(\mathrm{II})$ ion while changing from (BIK) $)_{3}$ to (BIK) $)_{2}(\mathrm{HBIP})$ environments.

The high temperature value of the $\chi_{\mathrm{m}} T$ product also enables the evaluation of the amount of Fe complexes grafted on the particles. At $300 \mathrm{~K}$, the expected $\chi_{\mathrm{m}} T$ of the coordinated complexes is $3 \times 10^{-3} \mathrm{~cm}^{3} \mathrm{~K} \mathrm{~g}^{-1}$ (see ESI $\dagger$ ). This expected value has been calculated taking into account that only Fe(II) complexes are present at the surface of the particles. The lower obtained $\chi_{\mathrm{m}} T$ value of $1.2 \times 10^{-3} \mathrm{~cm}^{3} \mathrm{~K} \mathrm{~g}^{-1}$ indicates that less $\mathrm{Fe}(\mathrm{II})$ is coordinated to the particles than expected, suggesting a certain amount of unreacted ligands or amino groups at the surface.

To assess this, the coverage level of the organic shell has been checked by titration of the amino groups available after APTES functionalization. The titration method involves the reaction of APTES with the chromophoric ( $\mathrm{N}$-(9H-fluoren2-ylmethoxycarbonyloxy)succinimide) specie that is detected by UV-Vis spectroscopy. The method is described as ESI $\dagger$ and gives an average coverage of free amino groups of $6.4 \times 10^{-25} \mathrm{~mol} \mathrm{~nm}^{-2}$ (0.4 amino group $\mathrm{nm}^{-2}$ or a surface of $2.5 \mathrm{~nm}^{2}$ per amino group) i.e. molecules separated by about $8.9 \AA$. This value is coherent with the reported values of $0.6 \mathrm{~nm}^{2}$ for the area occupied by grafted APTES molecule on silica (i.e. molecules separated by about $8.6 \AA$ A). ${ }^{53}$ In the crystal lattice of $\left[\mathrm{Fe}(\mathrm{BIK})_{3}\right]\left(\mathrm{BF}_{4}\right)_{2} \cdot 0.25 \mathrm{H}_{2} \mathrm{O}$, the closest $\mathrm{Fe}(\mathrm{II})$ ions are separated by an average distance of $c a$. $11 \AA$. It is then clear that at the 
surface of the particles, due to steric hindrance, two Fe complexes have to be separated by more than the distance separating two adjacent APTES molecules. A simple geometric model (ESI $\dagger$ ) can then show that the Fe(II) coverage evaluated by SQUID magnetometry properly fits the maximum coverage expected by examination of the structural data of $\left[\mathrm{Fe}(\mathrm{BIK})_{3}\right]\left(\mathrm{BF}_{4}\right)_{2} \cdot 0.25 \mathrm{H}_{2} \mathrm{O}$. Indeed, in the case where 4 grafted ligands out of 5 are not coordinated to $\mathrm{Fe}(\mathrm{II})$, the calculated $\chi_{\mathrm{m}} T$ value drops to $1.3 \times$ $10^{-3} \mathrm{~cm}^{3} \mathrm{~K} \mathrm{~g} \mathrm{~g}^{-1}$, a value in agreement with the obtained experimental data. The outer layer of the particles would thus be a mixture of $\mathrm{Fe}(\mathrm{II})$ complexes in a matrix of unreacted ligands suggesting, at first sight, a poor coverage of Fe(II). Nevertheless, this coverage is the best that can be obtained, taking into account the presence of the tetrafluoroborate counter-anions in the shell and the relative larger size of the complexes in comparison to small organic molecules such as APTES. This observation proves that HSTNs are appropriate platforms for expressing spin transition on nano-objects. Indeed, the very high coverage ratio of small ligands grafted at the surface of the particles enables the highest possible coverage of the complexes and reproduces the cooperativity level seen in bulk analogues.

\section{Experimental}

\section{Materials and methods}

Unless otherwise noted, all chemicals and solvents were analytical grade from Alfa-Aesar or Sigma-Aldrich and used without further purification. BIK and HBIP ligands were synthesized as previously published. ${ }^{45,46}$ FTIR spectra were recorded on a Tensor 27 spectrometer from Bruker Optics equipped with an ATR MVP2 module (diamond) from Harrick and a DTGS detector. 120 spectra were accumulated for reference and data in order to improve signal/noise ratio. UV-Vis spectra were recorded in solution on a Jasco V-670 spectrometer in $1 \mathrm{~cm}$ quartz vials. Reflectance spectra were recorded on a Cary 5000 from Agilent Technologies equipped with a DRA integrating sphere. The magnetic measurements were performed with a Quantum Design SQUID magnetometer MPMS-5S. This magnetometer works between 1.8 and $400 \mathrm{~K}$ for DC applied fields ranging from -5 to $5 \mathrm{~T}$. The dried powder samples were restrained in a polymer film (diamagnetism corrected) as a sample holder. DLS was carried out using a Malvern Zetasizer Nano with a DPSS laser at $532 \mathrm{~nm}$. Samples were prepared by taking $1.25 \mathrm{~mL}$ of colloid solution (typically $\sim 0.75 \mathrm{M} \mathrm{SiO}_{2}$ ) and diluting it in $30 \mathrm{~mL}$ of additional solvent (typically ethanol or acetonitrile). TEM images were recorded on a Tecnai spirit G2 cryomicroscope operating at $120 \mathrm{kV}$.

\section{Synthetic procedures}

General procedure for the preparation of silica nanoparticles. $5 \mathrm{~mL}$ of a solution of tetraethoxysilane (TEOS) in absolute ethanol $(0.90 \mathrm{M})$ are dropwise added to a solution of ammonia $\left(9.6 \times 10^{-2} \mathrm{M}\right)$ in a mixture of $46 \mathrm{~mL}$ of absolute ethanol and $10 \mathrm{~mL}$ of water. Vigorous stirring is maintained during 4 days during which time the solution turns turbid.
After 4 days, the nanoparticles are washed by 4 cycles of centrifugation and dispersion in absolute ethanol.

General procedure for APTES silanization. After washing, the nanoparticles are dispersed in $80 \mathrm{~mL}$ of absolute ethanol and $0.5 \mathrm{~mL}$ of 3-aminopropyltriethoxysilane is added. The colloidal suspension is stirred $1 \mathrm{~h}$ at room temperature and then heated at reflux for $1 \mathrm{~h}$. The particles are then washed by several cycles of centrifugation and dispersion in absolute ethanol.

General procedure for amidification. After drying, the silica nanoparticles are dispersed in a carbonate buffer solution $(\mathrm{pH}=9.5)$. Separately, $20 \mathrm{mg}\left(8.4 \times 10^{-5} \mathrm{~mol}\right)$ of HBIP and $16 \mathrm{mg}\left(8.4 \times 10^{-5} \mathrm{~mol}\right)$ of $N$-(3-dimethylaminopropyl)- $N^{\prime}$-ethylcarbodiimide hydrochloride (EDC) are dissolved in minimum amount of the buffer solution. This solution is added to the colloidal suspension of nanoparticles and the reaction is let to proceed at room temperature for $20 \mathrm{~h}$. The suspension is then centrifuged and the powder dispersed in water for washing. This cycle is repeated four times.

General procedure for the coordination of $\mathrm{Fe}$ (II) complexes at the surface of the functionalized nanoparticles. After amidification, the nanoparticles are dispersed in acetonitrile. Fe(II) tetrafluoroborate hexahydrate is dissolved in $2 \mathrm{~mL}$ of MeCN $\left(1 \times 10^{-3} \mathrm{M}\right)$ and this solution is added under an $\mathrm{Ar}$ atmosphere to the nanoparticles slurry that turns immediately light blue. After 10 min of stirring, a solution of BIK in MeCN $\left(3 \times 10^{-3} \mathrm{M}\right)$ is added to the mixture causing it to turn purple. After one night of stirring under an Ar atmosphere, a purple powder is obtained after centrifugation and washing several times with MeCN until the supernatant is free of any excess free $\left[\mathrm{Fe}(\mathrm{BIK})_{3}\right]^{2+}$.

\section{Conclusions}

In conclusion, we have demonstrated that confinement of molecular Fe(II) complexes in hybrid materials leads to ST properties close to those of monocrystals of similar compounds. Furthermore, we have developed a synthesis method, which allows for the building up of coordination compounds on spherical surfaces such as nanoparticles creating functional materials like HSTNs. This sequential synthetic strategy is relevant to study the influence of the size of the silica core on the coverage rate and therefore on the cooperativity of the ST system and its transition temperature. In fact, the appropriate choice of the ligands used for this study is perfectly adapted to the sequential synthetic strategy and enables an optimized surface coverage of the particles by the Fe(II) complexes. Our strategy can also be used for the implementation of room temperature SCO compounds for applications in the field of molecular electronics or sensors. This strategy is versatile and can be applied to other molecules with different physical properties as well as to other kinds of core materials. Such HSTNs can be implemented into macroscopic devices in a way that is much more achievable than purely bottom-up self-organization of molecules. Means of spray- or dip-coating on all kinds of substrates can lead to planar devices whereas dispersion in different kinds of 
matrixes (polymer, glass...) would lead to shape controlled macroscopic objects for the design of new functional materials. ${ }^{37}$

\section{Acknowledgements}

This research was made possible by NSF award CHE-1156907 "iREUSite: The US/France REU Exchange Site in Chemistry" made to the University of Florida.

\section{Notes and references}

1 A. Aviram and M. A. Ratner, Chem. Phys. Lett., 1974, 29, 277.

2 G. Maruccio, R. Cingolani and R. Rinaldi, J. Mater. Chem., 2004, 14, 542 .

3 T. D. Ladd, F. Jelezko, R. Laflamme, Y. Nakamura, C. Monroe and J. L. O'Brien, Nature, 2010, 464, 45.

4 J. Repp, G. Meyer, F. E. Olsson and M. Persson, Science, 2004, 305, 493.

5 E. Evangelio and D. Ruiz-Molina, Eur. J. Inorg. Chem., 2005, 2957.

6 P. Liljeroth, J. Repp and G. Meyer, Science, 2007, 317, 1203.

7 B. Fleury, M. Billon, F. Duclairoir, L. Dubois, A. Fanton and G. Bidan, Thin Solid Films, 2011, 519, 3732.

8 C. Rinfray, G. Izzet, J. Pinson, S. G. Derouich, J. J. Ganem, C. Combellas, F. Kanoufi and A. Proust, Chem. - Eur. J., 2013, 19, 13838.

9 C. Simao, M. Mas-Torrent, N. Crivillers, V. Lloveras, J. M. Artes, P. Gorostiza, J. Veciana and C. Rovira, Nat. Chem., 2011, 3, 359.

10 R. Sessoli, D. Gatteschi, A. Caneschi and M. A. Novak, Nature, 1993, 365, 141.

11 O. Sato, T. Iyoda, A. Fujishima and K. Hashimoto, Science, 1996, 272, 704.

12 S. Bonhommeau, T. Guillon, L. M. Lawson Daku, P. Demont, J. Sanchez Costa, J.-F. Létard, G. Molnár and A. Bousseksou, Angew. Chem., 2006, 118, 1655.

13 M. Ruben, J. Rojo, F. J. Romero-Salguero, L. H. Uppadine and J.-M. Lehn, Angew. Chem., Int. Ed., 2004, 43, 3644.

14 J. F. Letard, P. Guionneau and L. Goux-Capes, Top. Curr. Chem., 2004, 235, 221.

15 A. Bousseksou, G. Molnar, L. Salmon and W. Nicolazzi, Chem. Soc. Rev., 2011, 40, 3313.

16 O. Kahn and C. J. Martinez, Science, 1998, 279, 44.

17 N. T. Madhu, I. Salitros, F. Schramm, S. Klyatskaya, O. Fuhr and M. Ruben, C. R. Chim., 2008, 11, 1166.

18 A. Bousseksou, G. Molnar, P. Demont and J. Menegotto, J. Mater. Chem., 2003, 13, 2069.

19 M. Cavallini, I. Bergenti, S. Milita, G. Ruani, I. Salitros, Z.-R. Qu, R. Chandrasekar and M. Ruben, Angew. Chem., Int. Ed., 2008, 47, 8596.

20 M. Clemente-Leon, E. Coronado, M. Lopez-Jorda, J. C. Waerenborgh, C. Desplanches, H. F. Wang, J. F. Letard, A. Hauser and A. Tissot, J. Am. Chem. Soc., 2013, 135, 8655.
21 P. Gütlich, A. Hauser and H. Spiering, Angew. Chem., Int. Ed. Engl., 1994, 33, 2024.

22 A. Hauser, Spin Crossover in Transition Metal Compounds II, Springer Berlin Heidelberg, 2004, p. 155.

23 E. Collet, N. Moisan, C. Balde, R. Bertoni, E. Trzop, C. Laulhe, M. Lorenc, M. Servol, H. Cailleau, A. Tissot, M.-L. Boillot, T. Graber, R. Henning, P. Coppens and M. B.-L. Cointe, Phys. Chem. Chem. Phys., 2012, 14, 6192.

24 A. Tissot, C. Enachescu and M.-L. Boillot, J. Mater. Chem., 2012, 22, 20451.

25 P. Chakraborty, M.-L. Boillot, A. Tissot and A. Hauser, Angew. Chem., Int. Ed., 2013, 52, 7139.

26 I. Boldog, A. B. Gaspar, V. Martínez, P. Pardo-Ibañez, V. Ksenofontov, A. Bhattacharjee, P. Gütlich and J. A. Real, Angew. Chem., Int. Ed., 2008, 47, 6433.

27 F. Volatron, L. Catala, E. Rivière, A. Gloter, O. Stéphan and T. Mallah, Inorg. Chem., 2008, 47, 6584.

28 H. N. Peng, S. Tricard, G. Felix, G. Molnar, W. Nicolazzi, L. Salmon and A. Bousseksou, Angew. Chem., Int. Ed., 2014, 53, 10894.

29 Y. Raza, F. Volatron, S. Moldovan, O. Ersen, V. Huc, C. Martini, F. Brisset, A. Gloter, O. Stephan, A. Bousseksou, L. Catala and T. Mallah, Chem. Commun., 2011, 47, 11501.

30 A. Tokarev, J. Long, Y. Guari, J. Larionova, F. Quignard, P. Agulhon, M. Robitzer, G. Molnar, L. Salmon and A. Bousseksou, New J. Chem., 2013, 37, 3420.

31 R. M. van der Veen, O.-H. Kwon, A. Tissot, A. Hauser and A. H. Zewail, Nat. Chem., 2013, 5, 395.

32 R. M. van der Veen, A. Tissot, A. Hauser and A. H. Zewail, Phys. Chem. Chem. Phys., 2013, 15, 7831.

33 S. Titos-Padilla, J. M. Herrera, X.-W. Chen, J. J. Delgado and E. Colacio, Angew. Chem., Int. Ed., 2011, 50, 3290.

34 I. Suleimanov, J. S. Costa, G. Molnar, L. Salmon and A. Bousseksou, Chem. Commun., 2014, 50, 13015.

35 A. Hauser, J. Jeftić, H. Romstedt, R. Hinek and H. Spiering, Coord. Chem. Rev., 1999, 190-192, 471.

36 W. Stöber, A. Fink and E. Bohn, J. Colloid Interface Sci., 1968, 26, 62.

37 C. Sanchez, P. Belleville, M. Popall and L. Nicole, Chem. Soc. Rev., 2011, 40, 696.

38 Z. X. Li, J. C. Barnes, A. Bosoy, J. F. Stoddart and J. I. Zink, Chem. Soc. Rev., 2012, 41, 2590.

39 C. Sanchez, C. Boissiere, S. Cassaignon, C. Chaneac, O. Durupthy, M. Faustini, D. Grosso, C. Laberty-Robert, L. Nicole, D. Portehault, F. Ribot, L. Rozes and C. Sassoye, Chem. Mater., 2014, 26, 221.

40 I. George, P. Viel, C. Bureau, J. Suski and G. Lécayon, Surf. Interface Anal., 1996, 24, 774.

41 S. Tricard, B. Fleury, F. Volatron, C. Costa-Coquelard, S. Mazerat, V. Huc, C. David, F. Brisset, F. Miserque, P. Jegou, S. Palacin and T. Mallah, Chem. Commun., 2010, 46, 4327.

42 S. Tricard, C. Costa-Coquelard, F. Volatron, B. Fleury, V. Huc, P.-A. Albouy, C. David, F. Miserque, P. Jegou, S. Palacin and T. Mallah, Dalton Trans., 2012, 41, 1582. 
43 S. Tricard, F. Charra and T. Mallah, Dalton Trans., 2013, 42, 15835.

44 S. Tricard, Y. Raza, S. Mazerat, K. Aissou, T. Baron and T. Mallah, Dalton Trans., 2013, 42, 8034.

45 N. Braussaud, T. Rüther, K. J. Cavell, B. W. Skelton and A. H. White, Synthesis, 2001, 0626.

46 N. V. Fischer, F. W. Heinemann and N. Burzlaff, Eur. J. Inorg. Chem., 2009, 3960.

47 P. C. A. Bruijnincx, I. L. C. Buurmans, Y. X. Huang, G. Juhasz, M. Viciano-Chumillas, M. Quesada, J. Reedijk, M. Lutz, A. L. Spek, E. Munck, E. L. Bominaar and R. J. M. K. Gebbink, Inorg. Chem., 2011, 50, 9243.

48 A. Diebold and K. S. Hagen, Inorg. Chem., 1998, 37, 215.
49 E. Tronc, M. Nogues, C. Chaneac, F. Lucari, F. D'Orazio, J. M. Greneche, J. P. Jolivet, D. Fiorani and A. M. Testa, J. Magn. Magn. Mater., 2004, 272, 1474.

50 A. Mondal, Y. Li, P. Herson, M. Seuleiman, M.-L. Boillot, E. Riviere, M. Julve, L. Rechignat, A. Bousseksou and R. Lescouezec, Chem. Commun., 2012, 48, 5653.

51 A. Mondal, Switchable Molecular Magnetic Materials, UPMC, Paris, 2013.

52 A. Mondal, Y. L. Li, L. M. Chamoreau, M. Seuleiman, L. Rechignat, A. Bousseksou, M. L. Boillot and R. Lescouezec, Chem. Commun., 2014, 50, 2893.

53 T. G. Waddell, D. E. Leyden and M. T. Debello, J. Am. Chem. Soc., 1981, 103, 5303. 